\title{
Factors affecting the nitridation behavior of Fe-base, Ni-base, and Co-base alloys in pure nitrogen
}

\author{
J.J. Barnes and G.Y. Lai \\ Haynes International, Inc., Kokomo, Indiana, U.S.A.
}

\begin{abstract}
The behavior of alloys in nitrogen at high temperature is relevant to many industrial applications. Embrittlement due to internal nitride formation is the principal problem encountered in service. In this study, the nitridation resistance of a series of alloys in pure nitrogen at $1093{ }^{\circ} \mathrm{C}$ was investigated. For Fe-base, Ni-base, and Co-base alloys the amount of nitrogen absorbed and the nature and morphology of the nitrides formed was studied. It was found that alloys rich in nickel were most resistant to nitridation. Most of the alloys formed internal chromium nitrides. The Al-containing alloys with about $4.5 \mathrm{wt} \% \mathrm{Al}$, formed a surface scale of AlN and was very resistant to nitridation attack.
\end{abstract}

\section{Introduction.}

The use of nitrogen-rich atmospheres at high temperature is becoming increasingly common in industry. Nitrogen-rich atmospheres are used to protect materials from oxidation or, alternatively, to introduce nitrogen into the material. In powder metallurgy and electronics, nitrogen-based atmospheres are used to protect components from oxidation during sintering. In heat treating, nitrogen-based atmospheres are instrumental in case hardening of steel components. For all of these applications, the container materials, which are constantly exposed to nitrogen-rich atmospheres at high temperatures, must be resistant to nitrogen ingress. The ingress of nitrogen, followed by internal nitride formation, can result in embrittlement of an alloy.

Despite the fact that nitridation is a common phenomenon in industry, there have been relatively few investigations of the behavior of commercial alloys in nitrogen-rich atmospheres at high temperatures. The present authors [1] investigated the behavior of a wide range of commercial alloys in ammonia in the temperature range $649-1093^{\circ} \mathrm{C}$. That study showed a strong correlation between the nickel and colbalt content of an alloy and its nitridation resistance. Smith and Bucklin [2] investigated the nitridation behavior of a range of commercial alloys in nitrogen-based atmospheres and noted the best nitridation resistance for the highest nickel, lowest chromium alloy tested.

The aim of the present study was to examine the behavior in pure nitrogen of many of the commercial alloys whose behavior in amonia was characterized in the previous study [1]. The effect of alloy composition on nitridation kinetics and the nature of internal nitrides in this environment of higher nitrogen activity was examined. 

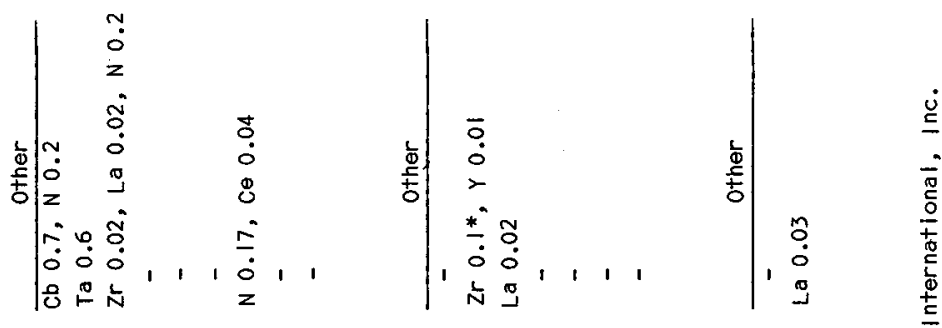

m

ن|

$F \mid 1,1+\frac{1}{0} 11$

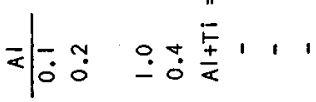

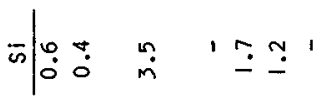

$\frac{c}{2} \mid:-1,1,1$,

$x \mid \ln 2 \ln$

$\sum \ln _{\text {in }}^{\circ}$

d。ำ

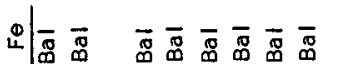

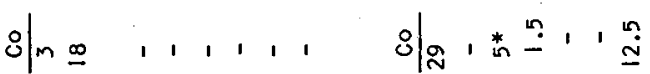

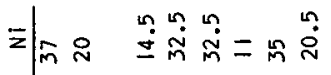

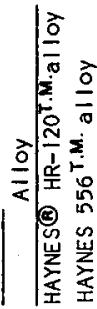

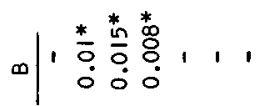

$\infty \mid 1 \quad$,

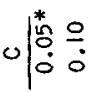

$F \mid 1$

$<1$,

$\bar{\omega} \mid \underline{\underline{m}}$

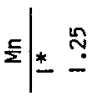

$=11 \pm$

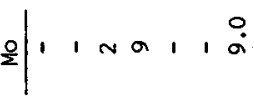

이. ,

$\left.\frac{1}{0}\right|_{\infty} ^{\infty} \approx$

๕|ำ

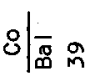

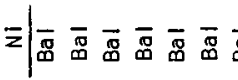

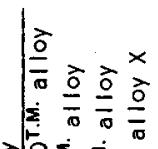

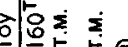

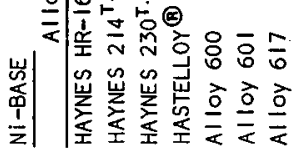

$\bar{z} \mid:$ ก

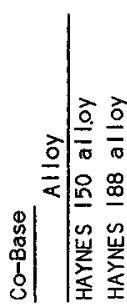

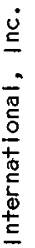

离 


\section{Experimental.}

A range of Fe-base, Ni-base and Co-base commercial alloys was investigated. The compositions of the alloys are given in table I. Coupons of the alloys were exposed in a tube furnace through which nitrogen was flowed at a rate of $150 \mathrm{~cm}^{3} / \mathrm{min}$. After exposure the samples were analyzed for nitrogen content using a LECO analyzer. In addition, the samples were sectioned and examined metallographically. X-ray diffraction of extraction residues was performed on selected samples and some samples were examined using SEM/EDAX.

\section{Results.}

The effect of alloy composition on nitridation behavior was studied by exposing alloys in $\mathrm{N}_{2}$ at $1093{ }^{\circ} \mathrm{C}$ for 168 hours and determining the amount of nitrogen absorbed. These data are shown in table II. The most resistant alloys were the high-nickel alloys 214, 230 and 600 . The Fe-base alloys, such as the stainless steel, 310SS, absorbed the greatest amount of nitrogen. It should be noted that many of the alloys were nitrided through the entire sample thickness in the 168 hours exposure period (see nitride depth measurements in Tab. II). Thus; the amount of nitrogen absorbed by these alloys is less than would have occurred if the samples had been thicker.

The change in nitrogen absorption with time was investigated for two of the alloys, 214 alloy and 230 alloy (Fig. 1). The 230 alloy exhibited parabolic kinetics with a parabolic rate constant, $k_{\mathrm{p}}$ of $9.6 \times 10^{-6} \mathrm{mg}^{2} \mathrm{~cm}^{-4} \mathrm{~s}^{-1}$, according to:

$$
\left(\frac{\delta N}{A}\right)=k_{\mathrm{p}} t
$$

where $\delta N / A$ is increase in nitrogen content per unit area in $\mathrm{mg} / \mathrm{cm}^{2}$ and $t$ is time in seconds. The rate of nitridation of the 230 alloy was much greater than that of 214 alloy. The 214 alloy did not exhibit parabolic kinetics - there was no measureable increase in nitrogen after 168 hours.

The depth of nitride formation was used in detemining the diffusivity of nitrogen for the Ni-base alloy, 230 alloy. The samples were exposed for 168,336 and 504 hours at $1093{ }^{\circ} \mathrm{C}$. The nitride depths were as follows: 168 hours $-0.46 \mathrm{~mm} ; 336$ hours $-0.57 \mathrm{~mm}$; 504 hours $-0.75 \mathrm{~mm}$. The calculations are described in the Discussion section.

The microstructures of nitrided Fe-base, Ni-base and Co-base alloys are shown in figure 2. The Fe-base alloy, 330SS (Fig. 2a) exhibited both grain boundary and intragranular nitrides. The nitride particles were fine at the surface and became coarser towards the center. It is clear from the greater depth of attack on grain boundaries that nitrogen diffusion on grain boundaries is greater than that within grains. The Ni-base alloy 617 in figure $2 \mathrm{~b}$ also exhibited grain boundary and intragranular nitrides. The alloy was through-nitrided and there were dark needle-shaped precipitated through-nitrided and exhibited dense intragranulare nitride formation close to the surface. Only one of the alloys tested, 214, did not exhibit internal nitride formation. This alloy formed a surface layer of aluminum nitride, which will be described below. 
Table II. - Nitrogen absorption and average internal penetration for the alloys exposed in $\mathrm{N}_{2}$ at $1093^{\circ} \mathrm{C}$ for 168 hours.

\begin{tabular}{|l|c|c|}
\hline Alloy & $\begin{array}{c}\text { Nitrogen absorbed } \\
\left(\mathrm{mg} / \mathrm{cm}^{2}\right)\end{array}$ & $\begin{array}{c}\text { Average internal } \\
\text { penetration }(\mathrm{mm})\end{array}$ \\
\hline 214 & 0.2 & 0 \\
600 & 1.1 & 0.41 \\
230 & 2.7 & 0.46 \\
188 & 3.7 & $>0.51$ \\
HR -160 & 3.9 & 1.19 \\
617 & 5.1 & 0.58 \\
X & 6.0 & 0.63 \\
RA330 & 6.6 & $>1.52$ \\
601 & 7.2 & $>0.59$ \\
RA85H & 8.5 & $>1.44$ \\
556 & 9.0 & $>1.52$ \\
150 & 9.0 & $>0.80$ \\
HR 120 & 9.6 & $>0.86$ \\
$253 \mathrm{MA}$ & 10.0 & $>1.50$ \\
$800 \mathrm{H}$ & 10.3 & $>1.50$ \\
$800 \mathrm{HT}$ & 11.4 & $>0.79$ \\
$310 \mathrm{SS}$ & 12.3 & \\
\hline
\end{tabular}

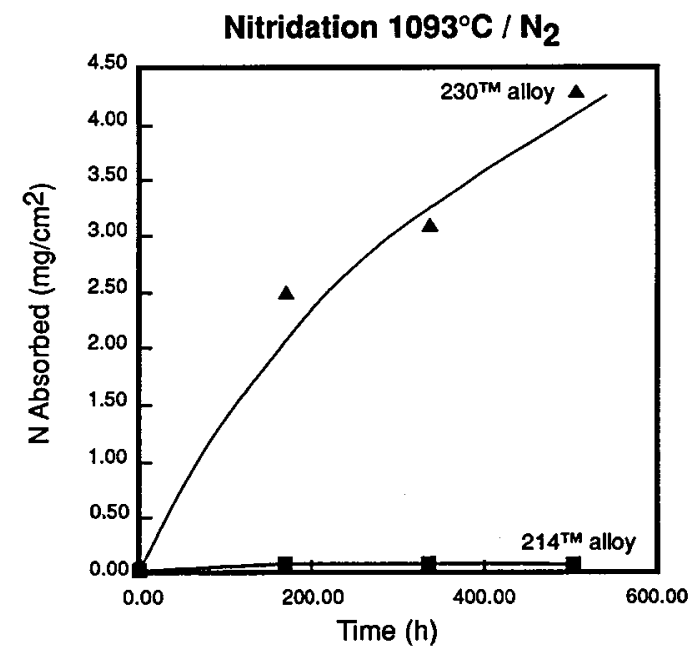

Fig. 1. - Kinetic data for 214 alloy and 230 alloy exposed at $1093^{\circ} \mathrm{C}$ in $\mathrm{N}_{2}$. 

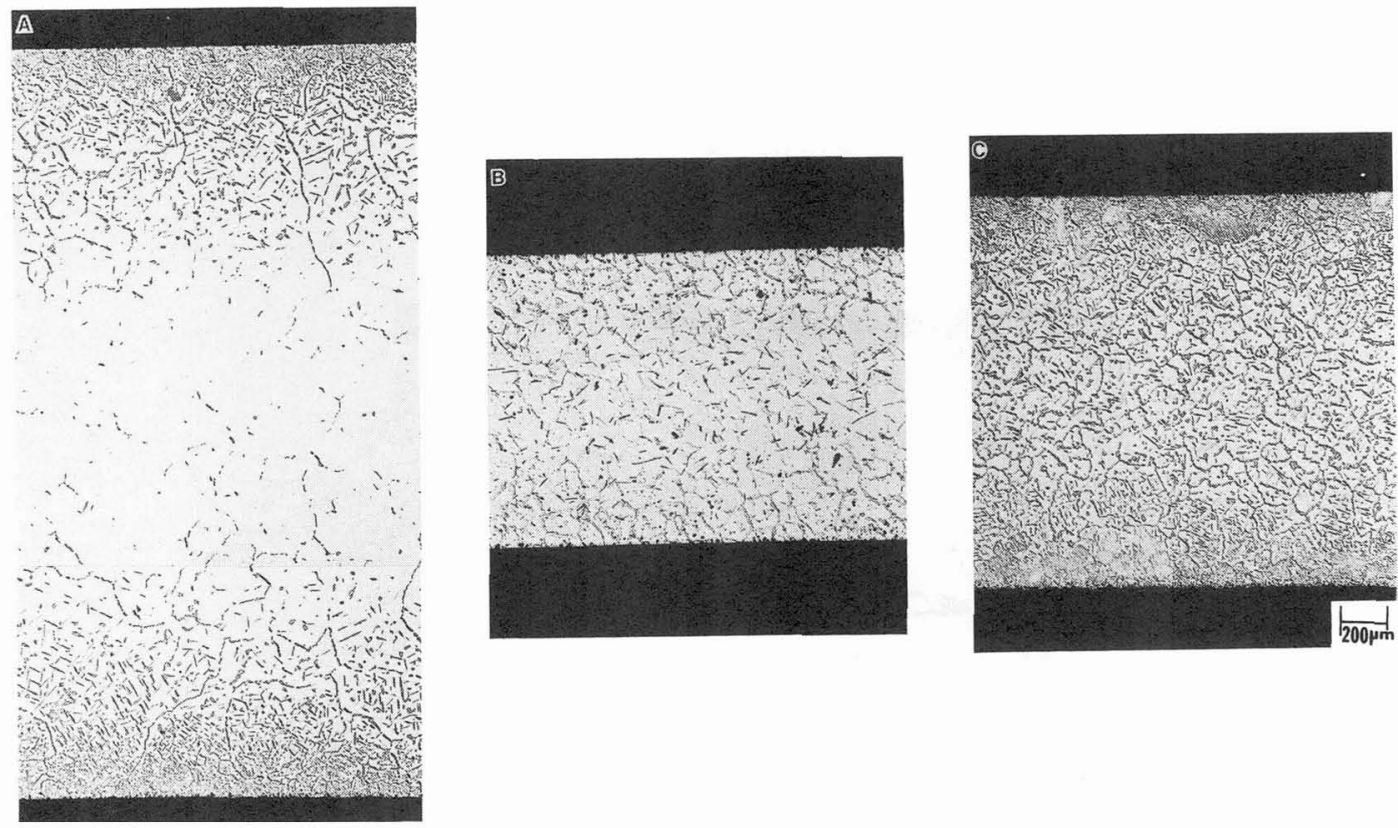

Fig. 2. - Optical micrographs showing internal nitridation in: a) 304SS; b) alloy 617; c) alloy 150 .

The morphologies and the nature of the nitrides formed in the various alloys were studied using X-ray diffraction and SEM/EDAX. The phases indentified by X-ray diffraction of extraction residues are given in table III. In most of the alloys $\mathrm{Cr}_{2} \mathrm{~N}$ was the predominant nitride phase. Some of the additional phases were: HR-160 alloy formed $\mathrm{CrN}$ and TiN; alloy 600 formed TiN; the $\mathrm{Al}$-containing alloys, RA85H, 601 and 617, formed AlN.

Table III. - X-ray diffraction analysis of extraction residue from samples nitrided at $1093{ }^{\circ} \mathrm{C}$ for 168 hours in $N_{2}$.

\begin{tabular}{|l|l|}
\hline Alloy & Phase detected \\
\hline $\mathrm{HR}-160$ & $\mathrm{CrN}, \mathrm{Cr}_{2} \mathrm{~N}, \mathrm{TiN}$ \\
600 & $\mathrm{Cr}_{2} \mathrm{~N}, \mathrm{TiN}$ \\
230 & $\mathrm{Cr}_{2} \mathrm{~N},(\mathrm{Cr}, \mathrm{Mo})_{12}(\mathrm{Fe}, \mathrm{Ni})_{8-\mathrm{x}} \mathrm{N}_{(4-\mathrm{z})}, \mathrm{M}_{6} \mathrm{C}$ \\
$\mathrm{RA} 85 \mathrm{H}$ & $\mathrm{Cr}_{2} \mathrm{~N}, \mathrm{AlN}$ \\
601 & $\mathrm{Cr}_{2} \mathrm{~N}, \mathrm{AlN}$ \\
150 & $\mathrm{Cr}_{2} \mathrm{~N}$ \\
617 & $\mathrm{Cr}_{2} \mathrm{~N}, \mathrm{AlN}$ \\
188 & $\mathrm{Cr}_{2} \mathrm{~N}$ \\
$214^{*}$ & $\mathrm{AIN}, \mathrm{Al}_{2} \mathrm{O}_{3}$ \\
\hline
\end{tabular}

(*) surface analysis 
The Al-containing alloy 601 formed needle-shaped particles which were shown by EDAX to be Al-rich. Figure 3 shows the globular chromium nitride phase which was present in addition to the AlN phase. The particles were present on grain boundaries and within grains and were generally discrete. In most cases the AlN particles were associated with chromium nitride particles.

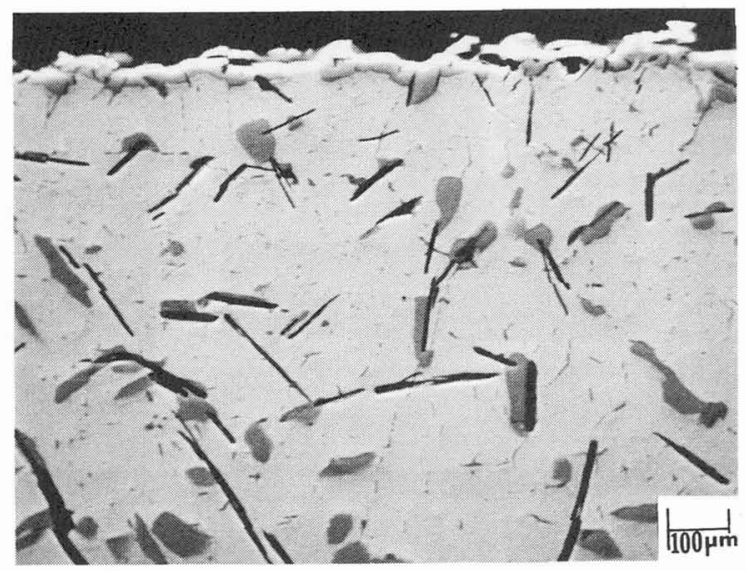

Fig. 3. - SEM micrograph showing internal nitrides in the Ni-Base, Al-containing alloy 601 after nitridation at $1093^{\circ} \mathrm{C}$ for 168 hours.

The nitride formed on 214 alloy was too thin to be identified after the 168 hours exposure, but after 500 hours at $1093^{\circ} \mathrm{C}$, the surface scale was found to be composed of AlN and $\mathrm{Al}_{2} \mathrm{O}_{3}$, with AlN predominating. The scale was examined in cross-section and was found to be continuous, thin and compact (Fig. 4).

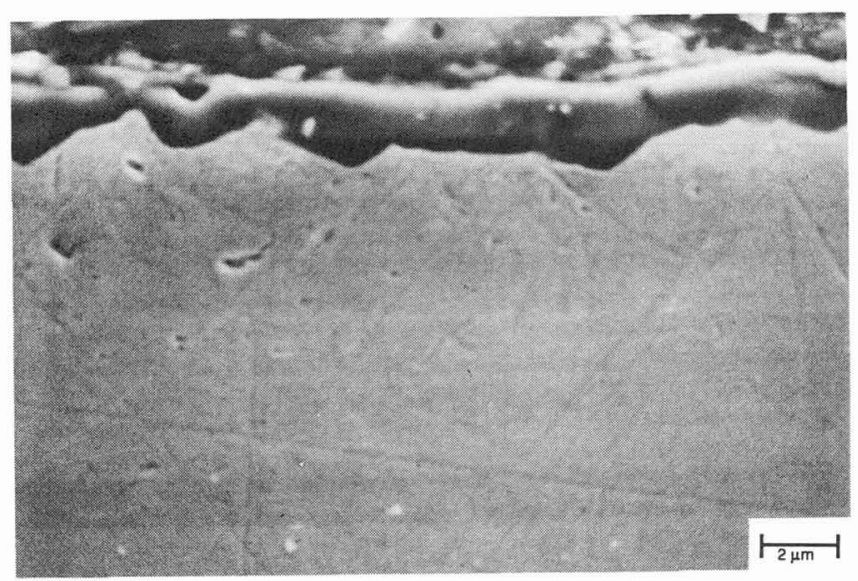

Fig. 4. - SEM micrograph showing thin aluminum nitride layer on 214 alloy. Sample exposed at $1093{ }^{\circ} \mathrm{C}$ for 504 hours. 


\section{Discussion.}

The nitrogen absorption data showed that the high-hickel alloys 214, 230 and 600 were the most resitant to nitridation. For 230 and 600 , this is most likely due to the effect of $\mathrm{Ni}$ in reducing the solubility of nitrogen in the alloy. It was established by Wriedt and Gonzalez [3] that increasing nickel decreased the solubility of nitrogen in Fe-Ni alloys at temperatures between 918 and $1277^{\circ} \mathrm{C}$. For 214 alloy, an aluminum nitride surface layer formed and was very effective in preventing nitrogen ingress.

It should be noted that for all of the alloys studied the magnitude of nitrogen absorption after exposure for 168 hours at $1093^{\circ} \mathrm{C}$ was considerably greater in nitrogen than in ammonia (see Ref. [1] for ammonia data). This is due to the fact that, although ammonia dissociates more readily than nitrogen on a metal surface [4], the nitrogen activity in pure $\mathrm{N}_{2}$ is much greater than that in cracked ammonia.

Most of the alloys studied formed internal chromium nitride. For a typical $\mathrm{Cr}_{2} \mathrm{~N}$-former, 230 alloy, the depth of nitride penetration at various times was used to calculate the permeability of nitrogen in the alloy and consequnetly the diffusivity. The calculation was performed using the equation of Wagner [5] by analogy with internal oxidation:

$$
\xi^{2}=\frac{2 N_{N} D_{\mathrm{N}}}{\nu N_{\mathrm{Cr}} t}
$$

where $\xi$ is nitride depth, $N_{\mathrm{N}}$ is solubility of nitrogen, $D_{\mathrm{N}}$ is diffusivity of nitrogen, $\nu$ is number of nitrogen atoms per chromium atom, and $N_{\mathrm{Cr}}$ is mole fraction of $\mathrm{Cr}$ in the alloy. This equation applies to the limiting case where the diffusion coefficient of the oxidant (in this case, nitrogen) is much larger than that of the metal which is internally nitrided. The square of the depth was plotted against time and the slope determined. The value of $\nu$ is 0.5 , since $\mathrm{X}$-ray diffraction data showed that the predominant nitride phase in the alloy is $\mathrm{Cr}_{2} \mathrm{~N}$. From these values a permeability $N_{\mathrm{N}} D_{\mathrm{N}}$ of $2 \times 10^{-10}$ was calculated. The value of $N_{\mathrm{N}}$ was estimated from the work of Wriedt and Gonzalez [3] as $0.0010 \mathrm{a} / \mathrm{o}$. This gives a diffusivity, $D_{\mathrm{N}}$, of $2 \times$ $10^{-5} \mathrm{~cm}^{2} \mathrm{~s}^{-1}$. For comparison, Rubly and Douglass [6] obtained a value of $6.7 \times 10^{-7} \mathrm{~cm}^{2} \mathrm{~s}^{-1}$ for a $\mathrm{Ni}-10 \mathrm{Cr}$ allloy at $800^{\circ} \mathrm{C}$.

As previously noted by Rubly and Douglass [6], the high diffusion rate of nitrogen compared to that of oxygen explains why an alloy such as 230 , which readily forms an external oxide scale in an oxidizing atmosphere, does not form an external nitride scale in a nitriding atmosphere. The critical solute level for the transition from internal to external nitridation is much greater than that for the transition from internal oxidation to external scale formation.

The presence of aluminum in an alloy was found to be important. Alloys containing Al formed internal AlN particles in addition to $\mathrm{Cr}_{2} \mathrm{~N}$ or, in the case of 214 alloy, formed a scale of AlN. The formation of AlN is easily explained given its thermodynamic stability. The phase is much more stable than the chromium nitrides, $\mathrm{CrN}_{\mathrm{N}}$ and $\mathrm{Cr}_{2} \mathrm{~N}$, and will form at a much lower nitrogen activity in an alloy. The alloys which formed internal AlN, i.e., RA85H, alloy 601 and alloy 617 , contained less than 2 wt\% Al. The 214 alloy, which formed a scale, contained $4.5 \mathrm{wt} \%$ Al. Thus, the critical solute concentration for the transition from internal nitridation to continuous nitride film formation is between 2 and $4.5 \mathrm{~W} / \mathrm{o}$ aluminum at $1093{ }^{\circ} \mathrm{C}$ for a chromium concentration of between 16 and $23 \mathrm{wt} \%$. The presence of aluminum in an alloy and the level of aluminum present is clearly of great practical importance. The internal nitrides of aluminum generally had a needle-shaped morphology and would 
contribute significantly to the embrittlement of an alloy. On the other hand, the presence of sufficient aluminum to form a protective scale, as in 214 alloy, greatly enhances the nitridation resistance of a material. Internal nitridation is prevented and embrittlement avoided.

The nitridation resistance of the 214 alloy is remarkable. The alloy was exposed at $1093^{\circ} \mathrm{C}$ in $\mathrm{N}_{2}$ for times up to 504 hours and showed very low levels of nitrogen absorption and negligible internal nitridation. The effect can apparently be attributed to a protective AlN scale formed on the alloy. Aluminum oxide was also detected on the surface and may influence the behavior of the alloy.

\section{Conclusions.}

1) High-nickel alloys were found to be most resistant to nitridation at $1093{ }^{\circ} \mathrm{C}$;

2) Most of the alloys formed internal $\mathrm{Cr}_{2} \mathrm{~N}$ particles. The aluminum-containing alloys with about 1 to $1.4 \mathrm{wt} \% \mathrm{Al}$ formed needle-shaped internal AIN particles. The 214 alloy, with $4.5 \mathrm{wt} \%$, formed a continuous surface layer of AlN;

3) The surface layer of AlN on 214 alloy proved to be very protective. The alloy showed very little nitrogen absorption at $1093^{\circ} \mathrm{C}$;

4) The Ni-base 230 alloy exhibited parabolic kinetics at $1093^{\circ} \mathrm{C}$. The diffusivity of nitrogen in the alloy was measured as $2 \times 10^{-5} \mathrm{~cm}^{2} \mathrm{~s}^{-1}$ at $1093^{\circ} \mathrm{C}$.

\section{References}

[1] B'ARNES J.J., LAI G.Y., Corrosion and Particle Erosion at High Temperatures, V. Srinivasan, K. Vedula Eds. (TMS, 1989) p. 617.

[2] SMITH G.D., BUCKLIN P.J., NACE Corrosion '86, paper 375.

[3] WRiedt H.A., GONZALES O.D., Trans. Metall. Soc. AIME 221 (1961) 532.

[4] Grabke H.J., Ber. Bunsenges. Phys. Chem. 72 (1968) 533.

[5] WAGNeR C., Corros. Sci. 5 (1965) 751.

[6] Rubly T.P., DOUGlass D.L., Oxid. Met. 35 (1991) 259. 